\title{
CONSTRUÇÃO DOS SENTIDOS NO TEXTO: PISTAS LINGÜÍSTICAS X PISTAS CONTEXTUAIS E DISCURSIVAS
}

Claudia Mendes Campos*

\section{Introdução}

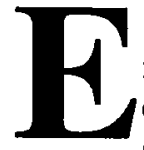

$\mathrm{m}$ trabalho anteriormente realizado, ${ }^{1}$ observei como, em contexto escolar, o produtor de textos por vezes se equivoca ao avaliar as estratégias de leitura do interlocutor, deixando a este a tarefa de, através de cálculo mental, inferir possíveis sentidos para o texto. Calcada na visão de Charolles (1983 e 1989), para quem a coerência é um princípio que regula tanto a produção quanto a interpretação do discurso, analisei um texto produzido em sala de aula por um aluno da $6 \mathrm{a}$. série do ensino fundamental. Se, de acordo com Charolles, o produtor fornece em seus textos instruções interpretativas conforme os sentidos que deseja construir e sua representação das capacidades interpretativas do interlocutor, era de esperar que não fossem encontrados problemas para a interpretação do texto analisado. No entanto, o contexto escolar, em sua artificialidade, mostra que nem sempre a produção

* Universidade Federal do Paraná

1 Comunicação apresentada no II Congresso Nacional da ABRALIN, realizado na UFSC, em Florianópolis-SC, em fevereiro de 1999. 
discursiva alcança com eficácia uma interpretação sem custo - pequeno que scja - para o interlocutor. No texto em questão, o aluno deixa de fornecer informações relevantes para o cálculo do sentido, provavelmente por pressupor conhecimento partilhado ou conhecimento de mundo por parte do interlocutor. O leitor precisa, assim, fazer uso de outros elementos do co-tex to e do contexto para preencher as lacunas deixadas pelo produtor e reconstruir um sentido para o texto.

Neste trabalho, retomarei aquela análise e darei continuidade a ela, procedendo à análise da segunda versão do mesmo texto. Observarei como se dá a atividade de releitura de seu texto pelo sujeito produtor, que modificações foram operadas e como algumas intervenções do professor na primeira versão influenciaram as alterações realizadas. Na oportunidade, retomarei ponto a ponto a análise anterior.

\section{A construção dos sentidos de acordo com Charolles}

Para que possa ficar claro o desenvolvimento de meu raciocínio, é necessário retomar alguns dos principais pontos da visão de Charolles (1983 e 1989) sobre a construção dos sentidos.

No trabalho de 1983, Charolles separa coerência de coesão. Ele defende a idéia de que a coerência é construída pelo interlocutor, diferentemente da coesão. $\mathrm{O}$ interlocutor faz uso dos recursos lingüísticos presentes no discurso para construir uma representação aceitável das relações nele denotadas.

A coerência é tida como um princípio para a interpretação do discurso porque o interlocutor sempre procura um sentido para os textos frente aos quais se coloca, um sentido que lhe pareça compatível com a intenção do produtor do texto. Ele levanta hipóteses para os enunciados que lhe parecem razoáveis para recuperar as relações de sentido que ele imagina o interlocutor quis estabelecer. Isto quer dizer que, se o interlocutor é capaz de construir uma interpretação para o texto, então este é coerente. Da mesma forma trabalha o produtor do texto, que é capaz de manejar com eficiência os recursos oferecidos por sua língua, de forma a fornecer, em seu texto, instruções interpretativas que levam em conta seu plano de comunicação e sua representação das habilidades interpretativas do interlocutor. É o que Charolles chama de "manejo inteligente dos mecanismos relacionais" (Charolles, 1989, p. 3). Isto é, para ele a coerência é também um princípio que governa a produção do discurso.

Em uma versão "idealística" (Charolles, 1989, p. 3) dessa hipótese, o produtor forneceria para o seu interlocutor todas as indicações relacionais 
relevantes para a apreensão da coerência do seu discurso. Contudo, nas situações reais de interação verbal, é desnecessário e até mesmo redundante fornecer todas as indicações: elas se fazem presentes através de outros meios, como as pistas discursivas e as informações contextuais. ${ }^{2}$

O sujeito que utiliza uma estratégia inteligente na produção de seus textos faz uma avaliação do trajeto a ser percorrido para atingir seu objetivo. Tal estratégia pressupõe um processo de decisões acerca das ações a executar para alcançar a interpretação do interlocutor.

Da mesma forma que o produtor utiliza estratégias inteligentes de ação, assim também o faz o interlocutor. Em uma situação em que haja ambigüidade, o leitor não leva em conta todas as interpretações possíveis já na primeira leitura. Ele opta por uma, a que lhe parece fazer sentido, e segue com ela. No caso de encontrar alguma dificuldade, ele volta à passagem relevante e a re-analisa, re-interpretando assim o texto e dando-lhe novo sentido. É interessante notar que ele não volta ao texto todo ou a passagens irrelevantes - por isso sua re-análise é considerada inteligente.

A estratégia do produtor está relacionada a ter uma representação das estratégias utilizadas pelo leitor e levá-las em conta no seu processo produtivo. Suas escolhas são determinadas pela sua representação da situação de recepção de seu texto, que diz respeito às "condições naturais" reguladoras das tarefas de interpretação (Charolles, 1989, p. 6).

Assim como o produtor pode tirar proveito da situação de recepção e não precisar desambigüizar seus enunciados para garantir a interpretação - no caso de o contexto e a situação de recepção o fazerem -, também pode ele dar informações a mais para evitar uma re-análise laboriosa ao interlocutor - no caso de o contexto e a situação de recepção pedirem tal recurso. Sem considerar o contexto e a situação de recepção, o produtor pode impor ao seu interlocutor um "árduo" cálculo mental (Charolles, 1989, p. 6) para restabelecer a coerência, re-interpretar o texto.

Se o produtor tem meios para evitar uma re-análise relativamente extensa para o interlocutor, ele provavelmente os usará. Por outro lado, ele pode ainda, intencionalmente, deixar de dar informações relevantes para a compreensão do texto, com o objetivo de "criar suspense". Assim, o interlocutor tem que chegar ao final da leitura para perceber que a sua interpretação inicial não faz sentido

2 Charolles lembra que, de um ponto de vista filosófico, sua hipótese não é "particularmente extravagante". De acordo com o princípio da cooperação, toda ocorrência discursiva é produzida para significar alguma coisa, fato que não pode ser ignorado pelo seu receptor nem pelo seu produtor. A coerência se constrói na interlocução: tanto o falante/escritor espera que seu discurso seja interpretado quanto o ouvinte/leitor espera poder interpretá-lo. 
e, então, proceder à re-análise das passagens relacionadas ao problema encontrado para poder interpretar o texto. Isso ocorre com frequiência em textos de humor. ${ }^{3}$

\section{O professor na reestruturação escolar de textos}

Charolles (1978) propõe a construção de uma gramática do texto, que possibilite determinar o conjunto das regras de boa formação textual. Sua preocupação advém da existência de julgamentos de desqualificação textual que não passam por qualquer modelo teórico. Comparando a formação textual e a formação frástica, lembra que em relação a esta última a gramática procedeu a uma substituição de "discriminações ingênuas radicais por marcas apreciativas teóricas (gramatical/agramatical)" (p. 40). O mesmo seria possível e desejável em relação ao texto, já que, de acordo com ele, existe um sistema de regras textuais, que constitui a "competência textual" do sujeito. Tal competência, assim como a frástica, seria encontrada em praticamente toda a comunidade linguística, excetuando-se apenas casos extremos como o de doentes mentais ou crianças. ${ }^{4}$

Seu estudo centra-se no trabalho escolar: nas intervenções feitas pelo professor nos textos dos alunos por julgá-los incoerentes. Estas se fazem por meio de "apreciações ingênuas", pré-teóricas. Charolles se questiona se já não seriam elas "uma ativação implícita" do sistema de regras subjacente à sua avaliação textual (p. 46), no entanto acaba por concluir que tais intervenções derivam de uma ausência de domínio teórico acerca da gramática do texto. Ao contrário das intervenções nas frases malformadas, aquelas relativas à má formação textual não são bem explicitadas pelo professor no texto do aluno: não se apresentam localizadas, não possuem caráter técnico, representam apenas uma compreensão global e não são propostos "exercícios sistemáticos de manipulação" (p. 44). Isto é, os professores mostram maior competência para lidar com problemas frásticos nos textos de seus alunos, deixando às questões textuais um tratamento periférico. Conforme veremos mais adiante, o mesmo ocorre com o dado aqui analisado.

3 Embora não seja cooperativa, também essa estratégia é inteligente, porque leva em conta as condições naturais de interpretação; a ausência de cooperação é intencional e tem um objetivo bastante claro.

4 Nesse caso qual seria então a funçāo do ensino da produção textual? O próprio autor se contradiz quando apresenta a análise de textos de alunos em que identifica a ausência de domínio sobre a construção da coerência textual. 
Geraldi (1991) entende texto como "uma seqüência verbal escrita coerente formando um todo acabado, definitivo e publicado" (p. 101), em que as expressões "verbal" e "escrita" representam delimitações que, embora não englobem todo e qualquer tipo de texto, constituem aqueles com os quais o autor pretende trabalhar. A idéia de "definitivo" visa restringir a concepção de texto à sua última versão, excluindo as partes do seu processo de construção, como os rascunhos por exemplo. Por "publicado", o autor entende "dado à leitura": o sentido é o de que todo texto pressupõe sua destinação a algum leitor, real ou imaginário. A importância que tem o outro na construção de um texto é a de que o produtor precisa fornecer pistas para que a reconstrução dos sentidos por parte do destinatário seja o mais próxima possível do pretendido. $O$ processo de construção dos sentidos pressupõe produtor e leitor. Os sentidos construídos não são, portanto, fixos: dependem tanto da produção quanto da leitura e são "resultado das estratégias de interpretação compartilhadas por uma comunidade lingüística" (p. 104).

Preocupado com o lugar do tex to no ensino da língua portuguesa, o autor identifica aí uma predominância do ensino gramatical e ressalta o papel de modelo conferido ao texto. Este é trabalhado como "objeto de leitura vozeada, de imitação e de fixação de sentidos" (p. 106 e 107), o aluno é levado a ler em voz alta de forma o mais próxima possível da leitura do professor, a produzir textos conforme os modelos estudados e a identificar no texto $o$ sentido pretendido pelo professor. Não é considerada a possibilidade de diferentes leituras que, mesmo sendo imprevistas, podem ser construídas .

Entre outras formas de inserção do texto no ensino de língua portuguesa, Geraldi defende o seu

reaparecimento, não com sentido fixo e único, mas como uma das condições necessárias e fundamentais à produção de sentidos na leitura; seus espaços em branco aceitos como inevitáveis, em função da natureza do próprio funcionamento da linguagem, com preenchimentos diferenciados não só em consequiência de diferentes interpretaçōes das estratégias de produção, mas também como conseqüência do pertencimento a universos discursivos diferentes (autor/leitor) e ao uso da linguagem em instâncias diferentes, tem seu preenchimento agenciado a partir do texto e das pistas que este oferece. (p. 111)

Ele propõe que o professor seja um interlocutor do aluno. Se tanto professor quanto aluno forem interlocutores um do outro, então a sala de aula 
poderá ser verdadeiramente um espaço de construção de sentidos, o que significa identificar no texto escrito e na interlocução os caminhos que possibilitam a leitura de um texto, a (re)construção dos seus sentidos através das pistas fornecidas.

Após longa crítica à gramaticalização do ensino de língua portuguesa, Geraldi propõe alternativas dentre as quais está a produção de textos entendida por oposição à redação escolar. Nesta, os textos são produzidos para a escola, sem qualquer comprometimento com o dito. Naquela, o sujeito é responsável pela articulação de um "ponto de vista sobre o mundo", ele se compromete individualmente com a sua construção de sentidos, ${ }^{5}$ mesmo que nada de realmente novo haja no seu discurso, mas o reaparecimento de "velhos conteúdos e velhas formas": se as articulações são diferentes, os sentidos construídos serão novos. A produção de textos é, então, aquela em que "se tenha o que dizer; se tenha uma razão para dizer o que se tem a dizer; se tenha a quem dizer o que se tem a dizer; o locutor se constitua como tal, enquanto sujeito que diz o que diz para quem diz; se escolham as estratégias para realizar os itens anteriores." (p. 137)

Sem uma preocupação explícita com o ensino de língua portuguesa, Koch (1997) apresenta uma concepção de texto coerente com a desenvolvida por Geraldi (1991). Para Koch, o texto é resultado de uma atividade verbal, a serviço de fins sociais, atividade esta consciente, criativa e interacional, em que há "o desenvolvimento de estratégias concretas de ação e a escolha dos meios adequados à realização dos objetivos" (Koch, 1997, p. 22). Daí se depreende que todo texto pressupõe uma interlocução, inserida em um contexto sociocultural, em que são construídos sentidos para os quais colaboram tanto o produtor, enquanto aquele que faz as escolhas lingüísticas compatíveis com sua intenção, quanto o interlocutor, que a partir das pistas da superfície textual e de "uma complexa rede de fatores de ordem situacional, cognitiva, sociocultural e interacional" (Koch, 1997, p. 25) constrói um sentido possível para o texto. De acordo com esta concepção, o sentido não está no texto, mas se constrói a partir dele; não existe $o$ sentido de um texto, mas possibilidades de sentido para ele.

Quando o que se identifica no trabalho do professor, ao corrigir (ao invés de ler) os textos de seus alunos, é uma preocupação exclusiva com aspectos formais, qual seria a concepção de texto em jogo? Acredito que em casos como

5 É preciso ressaltar que Geraldi não corrobora a visão da Análise do Discurso francesa, para a qual nada de novo se diz, todo discurso pertence a uma formaçāo discursiva e dentro dela só é possível repetir, há um assujeitamento. Embora não atribua ao sujeito o papel de fonte absoluta dos sentidos de seus textos, afirma a responsabilidade do sujeito pela articulação dos sentidos que, apesar de vinculados a uma formação discursiva, não são decorrência mecânica dela. 
esse, o professor entende os sentidos como já dados - se há algum problema para a compreensão, ele tenta inferir qual seja a intenção de seu aluno através de pistas contextuais discursivas, preenchendo assim as lacunas que puder, ou atribui a dificuldade de construção de um sentido ao mau uso das formas linguísticas. $\mathrm{O}$ texto é usado como um instrumento para ensinar as formas de dizer por escrito, sem que sejam aceitas variações além do previsto pelo professor. Não são consideradas nem aceitas as diferentes estratégias possíveis para dizer aquilo que se tem a dizer. $O$ aluno não é levado a definir interlocutores, reais nem imaginários, para seu texto, porque este será apenas corrigido, não terá de fato um interlocutor. Se não há interlocutor, não há possibilidade de atribuição de conhecimentos de mundo ou compartilhados, de capacidade para a produção de inferências, não há contexto nem interação. Ficamos diante da redação escolar, da qual tratou Geraldi (1991) entre tantos outros. É o texto produzido com o fim único de arrebatar uma nota, seu objetivo restringe-se ao funcionamento do mecanismo escolar, em que a construção de sentidos não é o que importa, apenas a perpetuação de conteúdos de ensino pré-estabelecidos. Será esse o caso do texto aqui analisado?

\section{O texto e sua segunda versão}

Primeira versão:

\section{A briga entre os Deuses}

Há muito tempo atrás um homem fez uma promessa a Hera, essa promessa dizia que se por acaso este homem se casasse, ele daria um de seus filhos à Deusa.

O pobre homem conseguiu se casar, e após dois anos de casado teve um lindo filho. Estava muito triste pois sabia que teria que entregar seu primeiro filho.

Ele resolveu não entregar seu filho. E a deusa Hera ficou muito furiosa, e de (como) castigo a raça humana resolveu dízimala, espalhando casamentos e depois muito cilimes.

Homens e mulheres se casavam, e depois de uma semana de casado, eles começavam a ter brigas terriveis.

Afrodite - a deusa do amor - vendo de cima de uma nuvem ficou horrorizada com aquelas cenas de falta de amor.

A humanidade sumiria da Terra em poucos meses. 
CAMPOS, C. M. Construção dos sentidos no texto: pistas lingǘŕsticas...

Afrodite mais do que depressa espalhou o amor entre as famílias. Mas ela sabia que aquilo nunca acabaria, pois Hera não era de desistir tão fácil.

E por isso Afrodite, mesmo não sendo de sua vontade deu seu próprio filho que acabara de ter com Hefesto.

Hera ficou muito magoada com sua nora (quem?). (Equal foi o resultado disso?)

E assim a humanidade não se acabou.

(Repense os parágrafos: você fala do mesmo assunto em vários parágrafos seguidos.)

(Ayrton, 6a. série)

(As palavras e os comentários destacados correspondem às anotações da professora.)

Segunda versão:

\section{A briga entre os Deuses}

Há muito tempo atrás um homem fez uma promessa a Hera, essa promessa dizia que se por acaso este homem se casasse, ele daria um de seus filhos à Deusa.

Após algum tempo este homem conseguiu se casar, e depois de dois anos de casado teve um lindo filho que se chamava João. Estava muito triste, pois sabia que teria que entregar João. Ele resolveu não dar seu filho à deusa Hera que ficou muito furiosa, e para castigar a raça humana resolveu destruila, espalhando casamentos e depois muito ciumes.

Homens e mulheres se casavam, e depois de uma semana de casados, eles começavam a ter brigas terriveis.

Afrodite, a deusa do amor, vendo de cima de uma nuvem ficou horrorizada com aquelas cenas de falta de amor.

A humanidade sumiria da Terra em poucos meses.

Afrodite mais do que depressa espalhou o amor entre as familias. Mas ela sabia que aquilo nunca acabaria, pois Hera não era de desistir tão fácil. E por isso Afrodite, mesmo não sendo de sua vontade, deu seu próprio filho que acabara de ter com Hefesto.

Hera ficou muito magoada com Afrodite e a partir disto nunca foi capaz de reunir todos os Deuses no Olimpo.

E assim a humanidade não se acabou.

$\mathrm{Na}$ análise da primeira versão, havia se identificado que o uso da expressão "por acaso" junto à explicação da promessa sugeria que o benefício almejado pela personagem com a promessa realizada era outro que não o do casamento, já que este não viria pelas mãos da deusa, mas como fruto do acaso. 
No entanto, o uso desta expressão não parece apresentar problemas para a professora; a sua leitura, quer da primeira versão quer da segunda, não questiona qual seja o benefício almejado. Uma possível explicação para esse fato seria o princípio da cooperação, já que, se não fosse o casamento o benefício envolvido na promessa, não seria possível reconstruir um sentido para o trecho em questão. A leitura do parágrafo seguinte ajuda a dirimir essa dúvida, porque ali está afirmado que o homem "conseguiu" se casar. Embora tal afirmação leve a uma interpretação que poderia ser considerada contraditória em relação ao sentido do primeiro parágrafo, ao mesmo tempo cla o esclarece: se o homem "conseguiu" se casar, é porque assim o desejava, e esse seria então o pedido feito à deusa. Não há, em nenhuma das versões, nada além de pistas contextuais esparsas e contraditórias - que conduzam a interpretação do leitor, a quem fica a tarefa do cálculo mental na tentativa de atribuir um possível sentido à passagem.

No segundo parágrafo da segunda versão, o autor substitui o adjetivo da expressão "pobre homem" pelo pronome demonstrativo "este"; nomeia a personagem do filho ("João"), de tal forma que no momento de retomar o referente pode utilizar o nome próprio, evitando a repetição de "filho". Ao fazê-lo, não soluciona um outro problema apontado por mim na análise anterior, mas que não se apresentou como tal para a professora: o de que havia incoerência entre a afirmação de que o homem daria um de seus filhos à deusa Hera, o que levaria à pressuposição de que fosse qualquer um deles, e a de que ele deveria entregar o primeiro filho. Embora na segunda versão não esteja dito que o primeiro filho é que deve ser entregue, a afirmação de que teria que entregar o filho que acabara de nascer, o único citado e portanto provavelmente o primeiro do casal, deixa a mesma dúvida inicial, que pode ser atenuada através da suposição, entre outras possíveis, de que na incerteza de se outros filhos viriam Hera teria exigido o primeiro. Não há informações explicitadas no texto que conduzam a interpretação nessa direção ou em qualquer outra, somente pistas discursivas. De novo, será o raciocínio do leitor, através de seu conhecimento de mundo, que possibilitará a produção de inferências para a solução desse problema na construção de um sentido para o texto. Contudo, as informações apresentadas no co-texto são suficientes para esclarecer o que de fato importa para o enredo: o filho que deveria ser entregue é aquele referido ao longo da história.

Outra alteração no segundo parágrafo é a troca do verbo "entregar" por "dar", cancelando a repetição daquele, que ocorrera na primeira versão. No terceiro parágrafo da primeira versão, ocorre a repetição da conjunção "e", problema que o produtor soluciona com a subordinação da segunda oração à primeira, através do uso do pronome relativo "que" ("que ficou muito furiosa"). 
A primeira repetição não havia sido apontada pela professora, somente a segunda.

A troca da expressão "de castigo à raça humana" por "para castigar a raça humana" evidencia que a destruição tem por finalidade o castigo. Essa relação também podia ser depreendida na primeira versão, sem a alteração: com a troca ela fica apenas mais explicitada. A preocupação da professora, ao marcar essa passagem, é com a forma, não com o sentido.

A substituição de "dízimala" por "destruila" parece se dever à impossibilidade, para o aluno, de identificar o problema apontado pela professora quando sublinhou aquela palavra na primeira versão. Isso porque a troca foi vocabular: não corrigiu o problema apontado; pelo contrário, o repetiu. $\mathrm{O}$ sentido, no entanto, não é prejudicado em nenhuma das versões. Apesar de não corresponderem à ortografia padrão do português, nenhuma das formas se diferencia do padrão a ponto de não poder ser compreendida.

Na primeira versão, fica ao leitor o trabalho de imaginar de que forma a atitude de Afrodite de dar seu filho a Hera aplacaria a fúria desta última. $O$ produtor não dá pistas que encaminhem uma leitura possível: o leitor terá que, através de seu raciocínio, criar algum contexto em que seja possível atribuir um sentido à passagem. Para o produtor essa informação não parece ser importante: basta-lhe apresentar o fato de que a ação de Afrodite é o que soluciona a complicação da narrativa. Ainda que o interlocutor não possa saber como isso se deu, o problema central da narrativa - o castigo que Hera impinge aos homens - é resolvido. E, de fato, essa passagem não dificulta a interpretação para a professora, que não faz aí qualquer anotação.

O uso da expressão "sua nora" na primeira versão leva a professora a fazer uma observação no texto: ela insere a pergunta "quem?" sobre a palavra "nora". O aluno, então, na segunda versão, a substitui pela expressão nominal "Afrodite", mais explícita que a anterior. Em nenhuma das duas versões está apresentada a relação existente entre Hera e Afrodite, portanto o leitor não tem como, através desse raciocínio, identificar o referente de "sua nora". No entanto, não parece haver dúvidas de que o referente seja de fato Afrodite. Caso o leitor não possua o conhecimento enciclopédico (da mitologia grega) necessário para estabelecer a referência, ele precisará fazer um cálculo interpretativo - voltar a passagens anteriores do texto e descobrir que, de acordo com a história relatada, somente uma personagem pode ter despertado a mágoa de Hera: Afrodite. Portanto, deve ser esta a "nora" de Hera, a quem o produtor se refere sem esclarecer o referente. Isto é, o interlocutor percorre um outro caminho, utilizando outras pistas que não as das relações familiares, para chegar à mesma interpretação: "sua nora" é Afrodite. 
Tentando dar conta da falta de ligação explícita entre, por um lado, a mágoa de Hera com Afrodite por esta ter entregado seu filho e, por outro, a solução do problema da narrativa (explicitado em: "E assim a humanidade não se acabou"), a professora pergunta ao aluno "qual foi o resultado" da mágoa de Hera. A sua anotação no texto não foi a mais feliz, isto é, não conseguiu esclarecer, para o aluno, que problema ela encontrara naquela passagem. Mesmo assim, ele tenta interpretar a pergunta da professora e resolver aquilo que ele entende como sendo o problema apontado. Na verdade, a sua "solução" acaba por acrescentar mais um problema ao texto, na medida em que insere uma nova informação, totalmente deslocada do restante da narrativa, sem qualquer relação com o contexto que seja facilmente apreensível. Parece se tratar mesmo somente de uma atividade escolar, de solução de um problema escolar, já que não percebemos aí nenhum trabalho efetivo sobre os possíveis sentidos da passagem.

A alteração na paragrafação, que provavelmente se deve à nota da professora para que o aluno repensasse a organização em parágrafos de seu texto, não interfere de forma direta na construção do sentido, embora represente tentativa do aluno de resolver os problemas apontados pelo seu leitor/professor.

A análise desse dado nos leva a um questionamento acerca das possibilidades de resultado caso a professora conseguisse centrar sua atenção, na leitura do texto, nas questões/problemas relativos ao sentido. Todas as vezes em que ela faz observações explícitas, obtém do aluno uma tentativa de adequação às necessidades do leitor (no caso, ela), sejam elas formais ou de sentido. Seria mais produtivo, conforme aponta Geraldi (1991), que o professor se posicionasse como um efetivo leitor do texto do aluno, com as preocupações próprias desse lugar - a (re)construção dos sentidos -, não como um corretor dos aspectos formais do texto, e apenas em alguns momentos dos seus aspectos semânticos.

\section{Considerações finais}

Tendo em mente a discussão, desenvolvida por Geraldi (1991), acerca do papel atualmente desempenhado pelo professor na escola, associada à reflexão acerca das anotações e comentários realizados pela professora nesse caso específico, que têm caráter predominantemente formal, vale fazer uma crítica da leitura por ela realizada - melhor dizendo, da correção por ela realizada. A questão fundamental de todo texto é a construção dos sentidos. É papel/função do professor estar atento a ela e mediar a produção de textos de seus alunos, colocando-se como um real interlocutor, que intenta auxiliá-los no 
CAMPOS, C. M. Construção dos scntidos no texto: pistas lingüísticas...

domínio das diferentes estratégias de produção escrita. Atitude esta que a professora em questão não demonstra no dado analisado.

Por outro lado, a partir do que pude observar nas anotações da professora no texto desse aluno, fica uma dúvida acerca da validade da análise que ressalta os problemas na coerência do texto. Por que para a professora eles não se mostraram como problemas? Provavelmente porque, tendo acesso a elementos contextuais que possibilitam a elaboração de hipóteses e tendo os conhecimentos de mundo necessários para a produção das inferências, ela constrói um sentido para o texto e não mais se dá conta do cálculo que realizou. Ocorre que o sentido se estabelece através de outras pistas - contextuais, discursivas - que não somente as coesivas. Junto a isso há o fato de que o raciocínio exigido talvez não represente um cálculo tão árduo como propus a princípio e o professor/leitor reponha as lacunas de sentido sem clara consciência dessa ação. Apesar de em vários pontos o produtor deixar a interpretação a cargo de um cálculo mental do leitor, este não falha: é possível construir um sentido para o texto em questão. Mesmo as passagens que poderiam ser consideradas como problemas de coerência por algum leitor específico são localizadas e não afetam a compreensão global.

\section{RESUMO}

A coerência é entendida por Charolles (1983) como um princípio regulador da interpretação do discurso, uma vez que o interlocutor levanta hipóteses que lhe parecem razoáveis para representar as relações de sentido que ele imagina tenham sido propostas pelo produtor do texto. Isto é, o interlocutor sempre procura um sentido - compativel com a suposta intenção do produtor - para os textos frente aos quais se coloca. Em trabalho de 1989, o autor acrescenta que a coerência é também um princípio que governa a produção do discurso, uma vez que o produtor fornece todas as indicações relacionais relevantes para a apreensão do sentido de seu discurso. Isto é, ele maneja com eficiência os recursos linguísticos oferecidos por sua língua, levando em conta seu plano de comunicação e sua representação das habilidades interpretativas do interlocutor. Neste trabalho, procuro observar tais aspectos da construção dos sentidos em contexto escolar, situação em que nem sempre o produtor alcança a eficácia proposta por Charolles. Procedo à análise da reestruturação de um texto produzido em sala de aula por um aluno de sexta série do ensino fundamental, na qual observo que o aluno não consegue identificar, na primeira versão de seu texto, as passagens que causam dificuldade à interpretação. Ao reestruturá-lo, os problemas relativos à coerência textual permanecem. 
CAMPOS, C. M. Construção dos sentidos no texto: pistas lingüísticas...

Uma das conclusões que daí decorrem é a de que a escola não foi capaz de auxiliar o aluno na realização de uma avaliação adequada das estratégias de leitura do interlocutor.

Palavras-chave: coerência, leitura, correção.

\section{ABSTRACT}

Charolles (1983) argues that coherence is a principle in the interpretation of discourse, since the receiver considers what is said to him shall be coherent. He manipulates the text so as to calculate a satisfactory coherence formula, taking into account the cohesion signals advanced by the utterer. Charolles (1989) expands the notion of coherence maintaining that it is also a principle governing discursive utterances, since the utterer gives the receiver all the relevant and necessary relational indications for $\mathrm{him} /$ her to grasp the coherence of the discourse. He is able to manage the linguistic means of his language efficiently, bering in mind his communication plan as well as his representation of the receiver's interpretative skills. In this article, we examine the interpretative process in school context where sometimes the utterer is unable to proceed as proposed by Charolles. The focus of this analysis is a rewritten classroom-produced text by a sixth grade elementary school student. In the rewriting task, the subject does not realize the interpretative problems of his text, and this prevents him from improving it. Thus, we are led to conclude that schooling may not have succeeded in helping the student to construct a proper representation of the receiver's interpretative strategies.

Key words: coherence, reading, correction.

\section{REFERÊNCIAS}

CHAROLLES, M. Introdução aos problemas da coerência dos textos. In: ALVES, C.; ORLANDI, E.; OTONI, P. (Orgs.). O texto: leitura e escrita. Campinas: Pontes Editores, 1978. 1983.

Coherence as a principle in the interpretation of discourse. Text, Amsterdã, 3 (1),

. Coherence as a principle in the discursive production. I $n$ : HEYDRICH, W.; NEUBAUER, F.; PETÖFI , J. (Eds.) Conexity and coherence. Berlin: De Gruyter, 1989. 
CAMPOS, C. M. Construção dos sentidos no texto: pistas lingüísticas...

GERALDI, J. W. Portos de passagem. São Paulo: Martins Fontes, 1991.

KOCH, I. V. O texto e a construção dos sentidos. São Paulo: Contexto, 1997. 